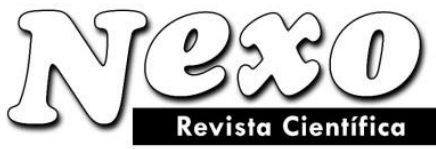

Vol. 33, No. 01, pp. 109-120/Junio 2020

\title{
AROMATICITY STUDY OF HETEROCYCLIC ANTICANCER COMPOUNDS THROUGH COMPUTATIONAL S-NICS METHOD
}

\section{ESTUDIO DE LA AROMATICIDAD DE LOS COMPUESTOS ANTICANCERÍGENOS HETEROCÍCLICOS MEDIANTE EL MÉTODO COMPUTACIONAL S-NICS}

\author{
Marzieh Shekarkhand ${ }^{1}$, Karim Zare ${ }^{1, *}$, Majid Monajjemi ${ }^{2}$, Elham Tazikeh-Lemeski ${ }^{3}$, Masoumeh \\ Sayadian $^{4}$ \\ ${ }^{1}$ Department of Chemistry, Science and Research Branch, Islamic Azad University, Tehran, Iran. \\ ${ }^{2}$ Department of Chemical Engineering, Central Tehran Branch, Islamic Azad University, Tehran, Iran. \\ ${ }^{3}$ Physical Chemistry Department of Chemistry, Gorgan Branch, Islamic Azad University, Gorgan, Iran. \\ ${ }^{4}$ Department of Chemistry, Eslamshahr Branch, Islamic Azad University, Eslamshahr, Iran. \\ k-zare@srbiau.ac.ir
}

(recibido/received: 17-octubre-2019; aceptado/accepted: 21-febrero-2020)

\begin{abstract}
In this study, we have sujessted a theoritical aproach via computing of nucleus-independent chemical shifts (SNICS) in view point of probes motions in a sphere of de-shielding and shielding spaces of rings of anticancer contain heterocyclic rings. Few research in theoretical of a statistical approach in NMR shielding and nucleus independent chemical shifts for study of anticancer drugs. S-NICS method is an accurate method for estimation the amount of aromaticity in the non-benzene rings such as heterocyclic rings which is a famous for organic chemical compounds as anti-cancer disease. Theoretical of a statistical method of NICS-nucleus independent chemical shift in small distance and are alternate in large distance in the center of heterocyclic rings. In this research, we have explored the statistical approaches through nucleus-independent chemical shifts-SNICS calculations in view point of $\mathrm{Bq}$ motions in the center of sphere spaces of heterocyclic rings of some anticancer drugs. The S-NICS method is an accurate computing method for estimation the aromaticity in the non-benzene rings such as heterocyclic rings which are standard molecules in organic anti-cancer compounds. Although NICS values for benzene and naphthalene and so on can be indicated as aromaticity criterion, for other molecules such as heterocyclic rings and their derivatives, S-NICS values are much more accurate compare to NICS index. Hetrocyclic compound with good $\pi$ stacks are good cacdidate for anticancer medicines. Precence of Nitrogen, oxygen and sulfur in these compounds make them similar biochemical parts such as nuclice acids and. Aromaticity of heterocyclic ring. This similarity especially them $\pi$ stacks give the the ability of interaction with DNAs and RNAs and the heterocyclic compounds.
\end{abstract}

Keywords: Heterocyclic Compounds; Anticancer drug; Aromaticity study; Computational S-NICS method. 


\section{RESUMEN}

En este estudio, hemos sugerido un enfoque teórico a través de la computación de los cambios químicos independientes del núcleo (S-NICS) en el punto de vista de los movimientos de las sondas en una esfera de espacios de desprotección y protección de anillos de anticancerígenos que contienen anillos heterocíclicos. Pocas investigaciones teóricas sobre un enfoque estadístico en el blindaje de RMN y los cambios químicos independientes del núcleo para el estudio de medicamentos contra el cáncer. El método S-NICS es un método preciso para estimar la cantidad de aromaticidad en los anillos sin benceno, como los anillos heterocíclicos, que es famoso por los compuestos químicos orgánicos como la enfermedad anticancerígena. Teórico de un método estadístico de desplazamiento químico independiente del núcleo NICS a pequeña distancia y se alternan a gran distancia en el centro de los anillos heterocíclicos. En esta investigación, hemos explorado los enfoques estadísticos a través de cálculos de SNICS-cambios químicos independientes del núcleo en el punto de vista de los movimientos $\mathrm{Bq}$ en el centro de los espacios de esfera de los anillos heterocíclicos de algunos medicamentos contra el cáncer. El método S-NICS es un método computacional preciso para estimar la aromaticidad en los anillos que no son de benceno, como los anillos heterocíclicos, que son moléculas estándar en los compuestos orgánicos contra el cáncer. Aunque los valores de NICS para benceno y naftaleno, etc., pueden indicarse como criterio de aromaticidad, para otras moléculas como los anillos heterocíclicos y sus derivados, los valores de $\mathrm{S}$ NICS son mucho más precisos en comparación con el índice de NICS. Los compuestos heterocíclicos con buenas pilas $\pi$ son buenos cacdidatos para medicamentos contra el cáncer. La precedencia de nitrógeno, oxígeno y azufre en estos compuestos los convierte en partes bioquímicas similares, como los ácidos nucleicos y. Aromaticidad del anillo heterocíclico. Esta similitud, especialmente las pilas $\pi$, dan la capacidad de interacción con ADN y ARN y los compuestos heterocíclicos.

Palabras clave: Compuestos heterocíclicos; Medicamento contra el cáncer; Estudio de aromaticidad; Método computacional S-NICS.

\section{INTRODUCTION}

Heterocyclic compounds (HCs) and families are good candidates for anticancer drug Heterocyclic compounds are known as anticancer drugs due they have targeted DNA and causing cancer cell demise. Heterocyclic compound played a vital actions in the metabolism of all cells; 6 (or sometimes 5) membered hetero-cycles including one to three heteroatoms. Recently, imidazole fragment has been attracting much concentration because of its role as attractive scaffold for biochemical active heterocyclic drugs (Mohammadian, N. K. et al, 2017).

Anticancer property of Heterocycles structures is Due to ambidentate nucleophilic centers i.e. mercapto and amino groups. thiadiazine derivatives, as heterocyclic compound, have been reported to have antimicrobial activity mainly due to $\mathrm{N}-\mathrm{C}-\mathrm{S}$ linkage in the skeleton of triazolothiadiazine and also possess anticancer activity (Fathima et al, 2019).

Subsequently, the study of intercommunication of complexes contain heterocyclic ligand with DNA has gained increasing interest, owing to its use in tumour treatment and molecular biology. DNA is the key component of the antitumor agent and stacking interaction with metal complexes is used to identify drug interaction strategy. Schiff base metal complexes liking with DNA by cleavage or binding mechanism. In common, the ternary compounds can be bonded to the nucleic acid via the groove and electrostatic binding mode, leading to intercalation (Nakhaei, E et al, 2018).

Literature review also exposes that a minor change in the structure of anticancer drugs can lead to quantitative and qualitative variations in biological action (Hokmabady, L et al , 2016).

Nexo Revista Científica / Vol. 33, No. 01, pp. 109-120 / Junio 2020 


\section{Marzieh Shekarkhand et al.}

The basis in DNA or RNA as Cytosine, thymine, and uracil, the basal are contain heterocyclic compound and also contain many consecutive hydrogen bond-donor and acceptor groups, which makes it ideal for studying of interaction of heterocyclic drug with them.[5]. Structurally, pyrimidines are heterocyclic, aromatic organic compounds with two nitrogen containing carbon ring structures at positions 1 and 3 of the six membered ring (Nakhaei, E et al, 2018).

The investigation of the drug-DNA bases interactions is essential and will recovered regarding the action mechanism of antitumor, antiviral drugs, and some carcinogenic compounds. A range of techniques have been engaged for the interactions study of some anticancer drugs with DNA. The antitumor activity of a drug is related to its molecular properties as well as to its interactions with different targets in cells (Spiegel, K, 2006).

A large number of the important heterocyclic compounds are used in the medical activities such as histidine and proline which are amino acids. It is notable pyridoxine, folic acid, thiamine, riboflavin B12 and E families of the vitamins are included of heterocyclic structures. heterocyclic- $(2 \mathrm{H})-1,2,3$ triazoles CA-4 analogues are generally classified as tubulin polymerization inhibitors with an anti-mitotic mechanism of 35 action, due to their ability to disrupt microtubule dynamics and hence mitotic spindle formation by binding to the same site as colchicine on tubulin dimers. These small molecule VDAs also induce hypoxia-driven necrosis of solid tumors, and are able to induce apoptosis by cell-cycle arrest (Joshi, M, 2019).

The nucleus-independent chemical shift (NICS) is a computational method that calculates the absolute magnetic shielding at the center of the ring taken with reversed sign. Negative NICS values indicate aromaticity and positive values antiaromaticity (Schleyer, 1972).

The nucleus-independent chemical shift (NICS) is a computational method that calculates the absolute magnetic shielding at the center of the ring taken with reversed sign. Negative NICS values indicate aromaticity and positive values antiaromaticity. For further investigation of aromaticity, another method called the harmonic oscillator model of aromaticity (HOMA) ( Kruszewski,1972). It has been applied, and is distinguished as a normalized sum of the squared deviations of bond length from the normal value (Stępien,, 2004). An aromatic compound has a HOMA value of one whereas a non-aromatic compound has the value (Jiao, 1998).

Schleyer et al. have proposed the use of the negative of the computed magnetic shieldings at or above the ring center, referred to as 'nucleus-independent chemical shifts' (NICS), as a simple and effective criterion for aromaticity. NICS, as an indicator of aromaticity, agrees well with the energetic, geometric, and magnetic criteria, and does not require increment systems for other references (Schreyer, 1998). To date, a new generation of molecularly targeted drugs is eagerly expected who's rational for suggestion new structure for anticancer drug or other type of drugs to investigate the activity to bibding DNA or cancer cell. ( Skander, 2012). The NICS values for molecules could be indicated as the aromaticity criterion, for other cases such as antidepress ant and anticancer compounds and their derivatives, S-NICS values are much more accurate compare to NICS index (Mollaamin, 2012).

In a concurrent study, NICS is also an actual probe of the individual rings in polycyclic systems.12 Most lately, Lecea et al.13 used NICS to characterize the in-plane aromaticity of 1,3-dipolar cycloaddition transition states, and only found evidence for the in-plane delocalization; the p (out-of plane) effects are negligible (Jiao, 1998). In recnt years Computation study in biological field especially on drugs attract the research attention (Mollaamin, 2012).

Newly aromaticity in terms of nucleus-independent chemical shifts in long distances of NICS $(1,2.5,3$, and 3.5) $\AA$, around the ring center, NICS (0), at the center of ring plane and aromatic ring current shielding (ARCS) were compared in numerous research. In small range of distances $(\mathrm{r}<0.3)$ there are no theoretical or mathematical reports of statistical tactic in nucleus independent chemical shift calculations, while the asymmetry ( $\mu$ and skew (k. parameters fluctuate in behavior around the center of rings. Several research in recent years were done by SNICS Investigation for drug development. Zakeri and monajemmi recently developed S-NICS Investigation for

Nexo Revista Científica / Vol. 33, No. 01, pp. 109-120 / Junio 2020 
Neurology and Psychiatry, Antidepressant and Antihistamine Drugs. They used theoretical of a statistical approach in NMR shielding and nucleus independent chemical shifts for study of antidepressant and antihistamine drugs (Zakeri, 2018). This research group also S-NICS method is an accurate method for estimation the amount of aromaticity in the non-benzene rings such as heterocyclic rings which is a famous for organic chemical compounds as anti-cancer disease. SamieiSoofi and coworkers Studied Gilan's environmental plants \& natural products as anti-cancer drugs by S-NICS method. They have optimized and discussed about several active compounds which are extracted from famous plants through NMR study. There are no works in theoretical of a statistical approach in NMR shielding and nucleus independent chemical shifts for study of antidepressant and antihistamine drugs, while the asymmetry $(\eta)$ and skew $(\kappa)$ parameters are fluctuated in small distances and are alternative in large distances in the center of heterocyclic rings for Matrine, Cytarabine, Gemcitabine and Vidarabine (Neda SamieiSoofi, 2018).

The majority of heterocycle compounds and typically common heterocycle fragments present in most pharmaceuticals currently marketed, alongside with their intrinsic versatility and unique physicochemical properties, have poised them as true cornerstones of medicinal chemistry (Zakeri,, 2018).

We have now employed the computed geometric properties and especially magnetic enhancements and NICS to characterize the aromaticity of several heterocylic anticancer drugs with different structure and groups. In this study, the major components of active parameters erocyclic rings and their aromaticity were investigating. The numerous random points around the center of those molecules have been produced by generation of pseudorandom numbers, which are distributed in a Gaussian function in the interval $[0,1)$. At last the aromaticity was used as parameter for anticancer activity.

\section{THEORETICAL BACKGROUND}

The total chemical shielding tensor $\sigma$ is a non-symmetric tensor which could be separated into three independent parameters: asisotropic, traceless symmetric, and traceless anti-symmetric (Aime, 1996). [The spherical tensor has been showed by Haeberlen and Mehring (Monajjemi, 2019). They have investigated fundamental tensors as

$$
\sigma=\sigma^{\text {iso(0)}}+\sigma^{\text {anti(1) }}+\sigma^{\text {sym(2) }}
$$

Aaromaticity of nucleus-independent chemical shifts, with NICS (0) For any further argument of statistical methods in S-NICS mainly in short range of distances, we exhibited that the asymmetry(ç)15 and skew(ê) 15 fluctuate around the center of rings.

The reduced anisotropy as:

$$
\left[\zeta=\left(\sigma_{\mathrm{zz}}-\sigma_{\text {iso }}\right)=\left(\sigma_{33}-\sigma_{\text {iso }}\right)\right]
$$

$[\mathrm{z}=(\mathrm{szz}-\mathrm{siso})=(\mathrm{s} 33-\mathrm{siso})](3)$ and anisotropy $(\Delta \sigma)$ with relation of $\Delta \sigma=\frac{3}{2} \zeta$ including shielding asymmetry (h) could be distinct as:

$$
\begin{aligned}
& \Delta \sigma=\sigma_{x x}-\frac{1}{2}\left(\sigma_{x x}+\sigma_{y y}\right) \\
& \eta=\left(\frac{\sigma_{x x}-\sigma_{y y}}{\zeta}\right)=\frac{3\left(\sigma_{x x}-\sigma_{y y}\right)}{2 \Delta \sigma}
\end{aligned}
$$

In several belongings of an axially symmetric tensor, $\left(\sigma_{y y}-\sigma_{x x}\right)$ will be zero and later $\eta=0$. However, the asymmetry $(\eta)$ parameter specifies that how much the line figure deviates since an axially symmetric tensor,

Nexo Revista Científica / Vol. 33, No. 01, pp. 109-120 / Junio 2020 
The shielding tensor could be stated as the sum of a symmetric, an anti-symmetric, and a scalar terms, which are rank 2, rank 1 and rank zero tensors individually as:

$$
\Omega=\Omega^{(0)}+\Omega^{(1)}+\Omega^{(2)}
$$

The total chemical shielding tensor " $\mathrm{r}$ " is a non-symmetric tensor that could be decayed into three independent tensors as:

(1), an isotropic component,

(2) a traceless symmetric component,

and (3) a traceless anti-symmetric component .

In spherical tensor illustration, as Haeberlen have pointed out, at a fundamental level tensors are better represented in spherical fashion, such that a general second-order property "s" may be engraved as $s=\operatorname{siso}(0))+\operatorname{santi}(1)+\operatorname{ssym}(2)(7)$, where the number in brackets denotes to tensor rank. Spherical tensors

This study is based on dummy atom in de-shielding spaces of heterocyclic rings for seeing the most abundant of points. The major purpose random data of several probes inside of de-shielding spaces is for understanding of anisotropic spin-spin interaction in short distances. A random points near to the center of those rings have been generated by Gaussian function between the interval $[0,1)$

\section{COMPUTATIONAL DETAILES}

All calculations were carried out by using Gaussian program. Among various functionals for DFT calculation, Becke's three parameter hybrid functional combined with Lee-Yang-Parr correlation functional designated B3LYP was used. Were optimized at the B3LYP/6-311+G* level of theory. Geometry optimizations and frequency calculations were carried out at B3LYP/6-311+G.

The NICS values at the geometrical centers of interest were calculated at the B3LYP/6-31G* level with B3LYP/6-311G* geometries using the Gaussian 94 program

\section{RESULTS AND DISCUSSION}

As declared above It should be illustrious that NMR parameters mainly depend on the local chemical bonding environment, inside a few angstroms of the nucleus under thought (Esrafili, 2009).

Optimization and NMR shielding constants with orientations of the principal data such as standard components, Haeberlen-Mehring and Herzfeld-Berger parameters for Buclizine, Cetirizine, loratacline, and Promethazine compounds in various statistical situations have been calculated and the data are listed in tables1. The isotropyin all NMR calculations are positive which shows negative values for aromaticity, but the slopes are decreased from the replacing from 0.1 to center. It is obvious that the difference between isotropies for NICS data can explain the quality.

Nuclear magnetic resonance (NMR) spectroscopy provides a sensitive measure of electronic charge distribution about the nucleus of interest. Many of NMR observables are caused from anisotropic chemical shielding interaction between nuclear spin and its environment (Sack, 1998).

For calculating NMR shielding tensors at both the Hartree-Fock and DFT levels of theory, using functionals which do not include a specific magnetic field dependent term, but which have yielded good accuracy for other chemical properties (Cheeseman, 1996).

Nexo Revista Científica / Vol. 33, No. 01, pp. 109-120 / Junio 2020 
Aromaticity in terms of nucleus-independent chemical shifts in long distances of NICS $(1,2.5,3$, and 3.5) $\AA$, around the ring center, NICS (0), at the center of ring plane and aromatic ring current shielding (ARCS) were compared in several studies. In short range of distances $(r<03)$ there are no theoretical or mathematical reports of statistical approach in nucleus independent chemical shift calculations, while the asymmetry and skew parameters fluctuate in behavior around the center of rings.

The isotropy in NMR calculations are positive which indicates negative values for aromaticity. It is obvious that the isotropies for NICS data would illuminate the quantity and quality of the aromaticity for some molecules, but those are not capable for expressing the mechanism as well as S-NICS.

In slight distance around the center, the asymmetric-parameter16 (h), and the skew17 (k), exhibited. gaussian distribution based on their fluctuation behavior, which is relate on its distance of molecular ring. In contrast, of that parameters, the isotropy 16-18 siso Has not a fluctuating behavior and increase in around the midpoint of the rings with a direct relationship. The slopes of that line is changed for various distances of heterocyclic compounds.

Optimization\& NMR constants with orientations of the principal components\& parameter for some heterocyclic target in has been calculated through DFT methods. In small distance around the center, the asymmetricparameter. NMR calculations are positive which specifies negative values for aromaticity. It is obvious that the isotropies for NICS data could elucidate the quantity and quality of the aromaticity for these molecules, but those are not proficient for maintaining the mechanism as well as S-NICS.

For an aromatic compound, HOMO-LUMO gaps must be large enough to prevent electron localization and fixation rather than the preferable and more stable delocalization bonding agreement (Jalbout, 2002).

The results showed that aromaticity differs depending on the criterion used. The NICS (0.5), HOMO-LUMO gap predict that aromaticity increases in heterocyclic species and anti-aromaticity decreases in other part of anticancer molecule

Table 1: Nucleus-independent chemical shifts (NICS, and Anisotropy) properties related to aromaticity for. Studied anticancer drugs.

\begin{tabular}{|l|c|c|}
\hline Molecule & $\chi$ (anniso) & NICS (0.0) \\
\hline & 3.3011 & 7.3089 \\
$\mathbf{1}$ & 22.8291 & 11.2267 \\
& 1.5534 & 11.0180 \\
\hline \multirow{2}{*}{} & 2.061 & 8.7939 \\
& 10.868 & 9.4343 \\
\hline $\mathbf{3}$ & 6.8668 & \\
\hline \multirow{4}{*}{} & 33.2676 & 9.9182 \\
& 12.1921 & -5.6579 \\
& 2.0619 & 9.5627 \\
$\mathbf{5}$ & 10.8680 & 8.739 \\
& 18.5042 & 9.4343 \\
\hline & 1.7318 & 0.7274 \\
$\mathbf{6}$ & 3.0295 & 11.0327 \\
& 3.4972 & 10.356 \\
& 15.2492 & 8.9144 \\
$\mathbf{7}$ & 1.1257 & 1.6786 \\
\hline \multirow{3}{*}{$\mathbf{8}$} & 15.2066 & 12.3185 \\
& 33.0340 & -1.5720 \\
& 14.9072 & 1.61169 \\
\hline
\end{tabular}

Nexo Revista Científica / Vol. 33, No. 01, pp. 109-120 / Junio 2020 
Contributions perpendicular to the ring plane. The NICS (0.0) values for molecule 1 , suggesting the nonaromatic or weakly aromatic. Molecule 3 in middle ring showed negative NICS value that showed it would have high interaction with cancer cell and DNA and its pyridine and purine bases. In molecule 7 there is 3ring one ring contain hydroxyl group hase NICs negative and has aromaticity and other rings with oxygen and ketone group hase a few antiaromaticity and other ring with 5 Carbone has high antiaromaticity Molecule 8 has weakly antiaromaticy and has high ability to interact with DNA bases.

The isotropy in all NMR calculations are positive which indicates negative values for aromaticity. It is obvious that the isotropies for NICS data can explain the quantity and quality of the aromaticity for some molecules, but those are not able for expressing the mechanism as well as S-NICS.

The isotropy ( siso* $^{*}$ ) which is related to all of $\left(\mathrm{h}^{*}\right),\left(\mathrm{k}^{*}\right),\left(\mathrm{W}^{*}\right)$ and $\left(\zeta^{*}\right)$ is suitable criterion for the aromatic molecules both hetero or regular rings through the S-NICS method. Similar to the NICS method, in S-NICS15, mines nucleus-independentchemical-shifts indicates the aromaticity. Therefor "+" values indicate the antiaromaticity quantitative. In S-NICS15 methods, the shielding\& de-shielding15 spaces are important for discussing the mechanism of the aromatic molecules in point of ring currents (Monajjemi, 2015).

Nucleus-independent chemical shift values (NICS) show a little and no evidence of ring currents, indicating with no aromaticity for molexcule due to the high Anisotropy parameter.

Some criteria for explanation of aromaticity can be reflected and may divide into five categories, which are: (1) the energetic approach to aromaticity (2) geometrical considerations (3) reactivity of aromatic compounds (4) magnetic parameters of aromaticity, 8-10 and the (5) Statistical-Nucleus-Independent Chemical Shifts approach (SNICS) which is the subject of this study.

The stabilities S-NICS criterion is strongly affected on the greatest places in shielding spaces which is related to the composition of hetero aromatic rings. It is noticeable that geometry factors cause changes in the magneticfeld 15 by the nuclei and variation the resonant frequencies. Therefore, the chemical shielding and several factors as the same electronegativity, magnetic anisotropy of $\mathrm{p}$-systems will be changed due to the number of electrons the chemical shielding is a vector orientation function for all of the shielding parameters that may change in several places inside the shielding region.

Analogous to the NICS method, in S-NICS, negative nucleus-independent-chemical-shifts denote aromaticity. There for positive values denote anti-aromaticity. In S-NICS methods, the shielding and de-shielding spaces are important to discuss the mechanism of the aromatic molecules in point of ring currents, which are the circulating $\pi$ electrons in an aromatic molecule produce reverse to the functional magnetic field (Zakeri, 2018).

\section{CONCLUSION}

By the S-NICS, we have developed a steady method based on NMR performance of the magnetic components. Although this method is not simple compared to NICS, it has many benefits, such as its individuality of the shape and structure of the molecule, and independence of the center of the molecule. It is, more logically, dependent on inspection of the shielding area around each molecule or bio-molecule. Not only does this method work as a new criterion of aromaticity, but also it is potentially very useful in other fields such as nano-biotechnology, including protein folding, protein structure determination, DNA pairing mechanism, and t-RNA-amino acid binding, that are sensitive to proton chemical shifts from structural and conformational changes. Molecule 3 and 7 showed more aromaticity than other molecules and expect have extra interaction with DNA and genome of cancer cells. High aromaticity of heterocyclic rings results the high interaction of anticancer drug with DNA and cancer cell. The charge density as aromaticity of bioactive atoms in anticancer drugs. Decreases the amount of such a significant interaction and then the pharmacological characteristics of these drugs would be decreased. Charge

Nexo Revista Científica / Vol. 33, No. 01, pp. 109-120 / Junio 2020 
and aromarticity have an important role in determining the binding affinity and then reactivity of these ligands with the cancer cell receptor or mutant DNA of cancer cell genetics.

Fig.1: Optimization of structure of anticancer drugs

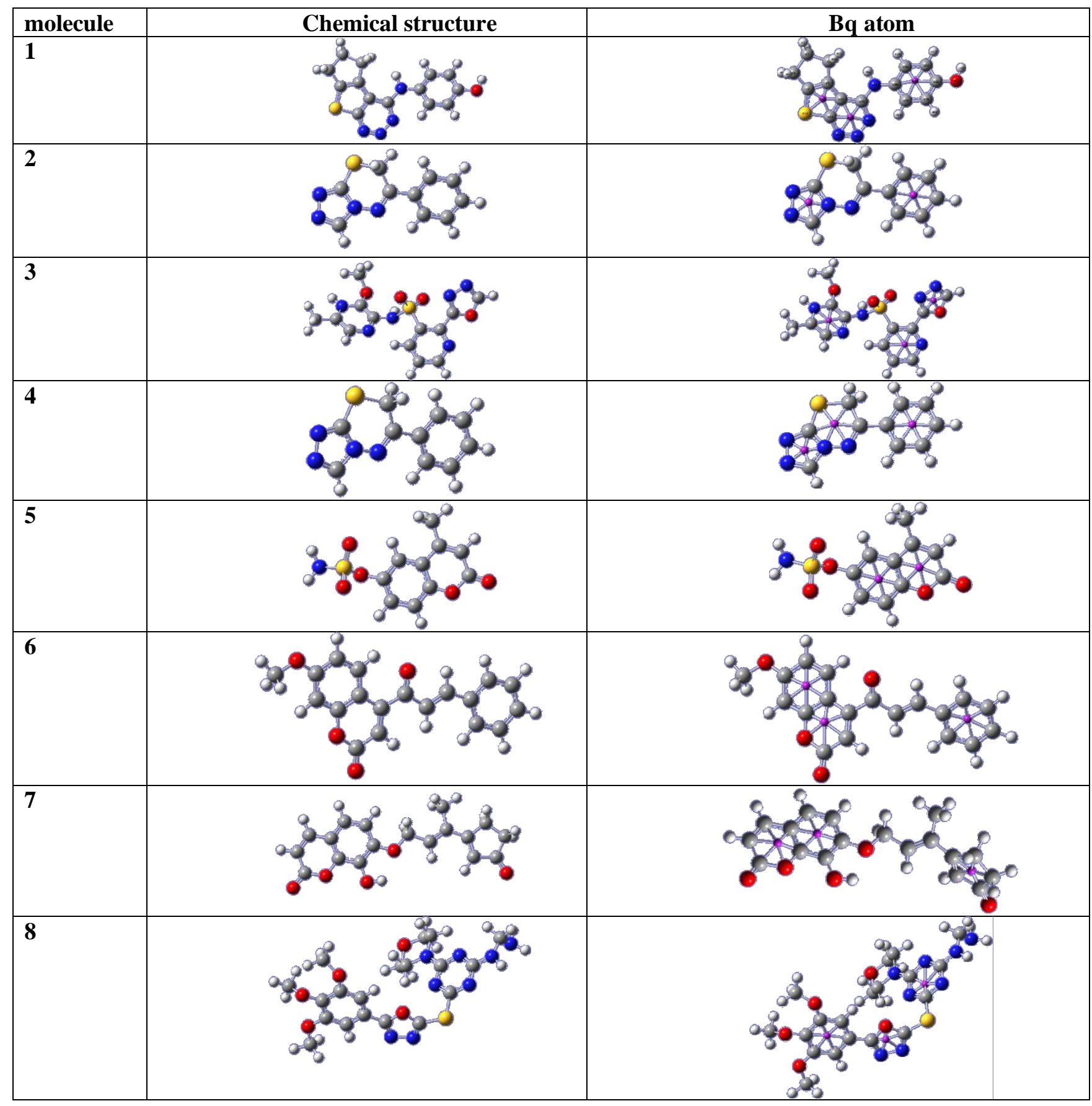

Nexo Revista Científica / Vol. 33, No. 01, pp. 109-120 / Junio 2020 
Marzieh Shekarkhand et al.

Table 2: S-NICS calculation for center rings

\begin{tabular}{|c|c|}
\hline Mol 1 & $\begin{array}{l}33 \text { Bq Isotropic }=7.3089 \text { Anisotropy }=3.3011 \\
X X=8.9990 \mathrm{YX}=0.5127 \mathrm{ZX}=0.7365 \\
\mathrm{XY}=1.0475 \mathrm{YY}=4.4994 \mathrm{ZY}=0.3037 \\
\mathrm{XZ}=0.7122 \mathrm{YZ}=-1.6082 \mathrm{ZZ}=8.4284 \\
\text { Eigenvalues: } 4.2268 \text { 8.1903 9.5097 } \\
\text { 34 Bq Isotropic }=11.2267 \text { Anisotropy }=22.8291 \\
\mathrm{XX}=9.8265 \mathrm{YX}=5.6476 \mathrm{ZX}=-1.2200 \\
\mathrm{XY}=3.4396 \mathrm{YY}=25.0071 \mathrm{ZY}=3.0936 \\
\mathrm{XZ}=-1.5137 \mathrm{YZ}=2.3058 \mathrm{ZZ}=-1.1536 \\
\text { Eigenvalues: }-1.73518 .969026 .4461 \\
35 \mathrm{~Bq} \text { Isotropic }=11.0180 \text { Anisotropy }=1.5534 \\
\mathrm{XX}=11.4526 \mathrm{YX}=-0.1603 \mathrm{ZX}=0.1610 \\
\mathrm{XY}=-0.2122 \mathrm{YY}=11.9956 \mathrm{ZY}=-0.1265 \\
\mathrm{XZ}=0.1223 \mathrm{YZ}=0.2558 \mathrm{ZZ}=9.6056 \\
\text { Eigenvalues: } 9.592211 .408112 .0536\end{array}$ \\
\hline Mol 2 & 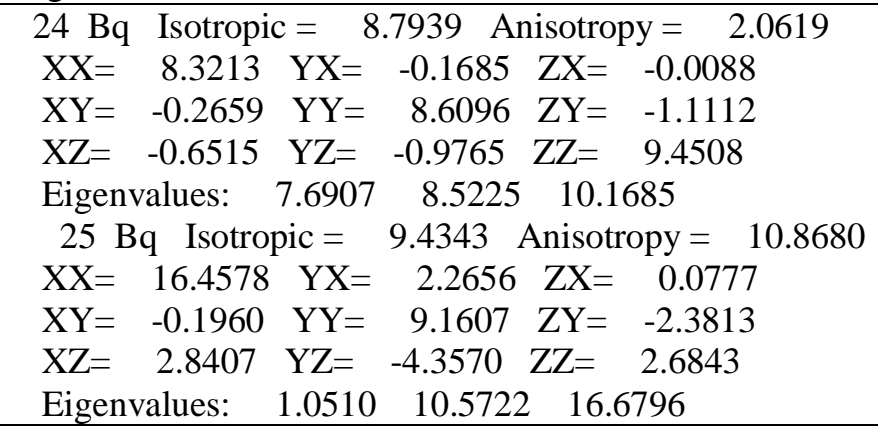 \\
\hline Mol 3 & $\begin{array}{l}38 \text { Bq Isotropic }=9.9182 \text { Anisotropy }=6.8668 \\
\mathrm{XX}=8.6725 \mathrm{YX}=0.2872 \mathrm{ZX}=1.3348 \\
\mathrm{XY}=1.5632 \mathrm{YY}=7.9683 \mathrm{ZY}=1.1418 \\
\mathrm{XZ}=4.0181 \mathrm{YZ}=-0.0215 \mathrm{ZZ}=13.1139 \\
\text { Eigenvalues: } 6.99808 .260614 .4961 \\
39 \text { Bq Isotropic }=-5.6579 \text { Anisotropy }=33.2676 \\
\mathrm{XX}=11.8994 \mathrm{YX}=-7.4329 \mathrm{ZX}=13.0170 \\
\mathrm{XY}=-7.2409 \mathrm{YY}=4.0631 \mathrm{ZY}=16.1839 \\
\mathrm{XZ}=11.8736 \mathrm{YZ}=16.1535 \mathrm{ZZ}=-32.9361 \\
\text { Eigenvalues: }-42.72139 .227116 .5205 \\
40 \mathrm{~Bq} \text { Isotropic }=9.5627 \mathrm{Anisotropy}=12.1921 \\
\mathrm{XX}=9.1856 \mathrm{YX}=-3.3443 \mathrm{ZX}=3.1778 \\
\mathrm{XY}=-3.4212 \mathrm{YY}=9.4596 \mathrm{ZY}=-5.2563 \\
\mathrm{XZ}=2.5222 \mathrm{YZ}=-6.0538 \mathrm{ZZ}=10.0429 \\
\text { Eigenvalues: } 4.01956 .977917 .6907\end{array}$ \\
\hline Mol4 & $\begin{array}{l}24 \mathrm{~Bq} \text { Isotropic }=8.7939 \text { Anisotropy }=2.0619 \\
\mathrm{XX}=8.3213 \mathrm{YX}=-0.1685 \mathrm{ZX}=-0.0088 \\
\mathrm{XY}=-0.2659 \mathrm{YY}=8.6096 \mathrm{ZY}=-1.1112 \\
\mathrm{XZ}=-0.6515 \mathrm{YZ}=-0.9765 \mathrm{ZZ}=9.4508 \\
\text { Eigenvalues: } 7.69078 .522510 .1685 \\
25 \mathrm{~Bq} \text { Isotropic }=9.4343 \text { Anisotropy }=10.8680 \\
\mathrm{XX}=16.4578 \mathrm{YX}=2.2656 \mathrm{ZX}=0.0777 \\
\mathrm{XY}=-0.1960 \mathrm{YY}=9.1607 \mathrm{ZY}=-2.3813 \\
\mathrm{XZ}=2.8407 \mathrm{YZ}=-4.3570 \mathrm{ZZ}=2.6843 \\
\text { Eigenvalues: } 1.051010 .572216 .6796\end{array}$ \\
\hline Mol5 & $\begin{array}{l}27 \mathrm{~Bq} \text { Isotropic }=0.7274 \text { Anisotropy }=18.5042 \\
\mathrm{XX}=5.8888 \mathrm{YX}=2.2319 \mathrm{ZX}=3.8466 \\
\mathrm{XY}=0.2745 \mathrm{YY}=12.8426 \mathrm{ZY}=-1.1163\end{array}$ \\
\hline
\end{tabular}

Nexo Revista Científica / Vol. 33, No. 01, pp. 109-120 / Junio 2020 


\begin{tabular}{|c|c|}
\hline & $\begin{array}{l}\mathrm{XZ}=3.8743 \mathrm{YZ}=-0.7095 \mathrm{ZZ}=-16.5492 \\
\text { Eigenvalues: }-17.23576 .354313 .0635 \\
\text { 28 Bq Isotropic }=11.0327 \text { Anisotropy }=1.7318 \\
\mathrm{XX}=9.9300 \mathrm{YX}=-0.4244 \mathrm{ZX}=-0.5949 \\
\mathrm{XY}=-0.2243 \mathrm{YY}=11.8880 \mathrm{ZY}=0.2720 \\
\mathrm{XZ}=-0.9446 \mathrm{YZ}=0.3139 \mathrm{ZZ}=11.2801 \\
\text { Eigenvalues: } 9.567611 .343212 .1872\end{array}$ \\
\hline Mol6 & $\begin{array}{l}38 \mathrm{~Bq} \text { Isotropic }=10.1356 \text { Anisotropy }=3.0295 \\
\mathrm{XX}=11.3059 \mathrm{YX}=1.2794 \mathrm{ZX}=-0.3279 \\
\mathrm{XY}=0.6071 \mathrm{YY}=10.9663 \mathrm{ZY}=-0.5011 \\
\mathrm{XZ}=-0.4013 \mathrm{YZ}=-0.1671 \mathrm{ZZ}=8.1345 \\
\text { Eigenvalues: } 8.073610 .177912 .1553 \\
\text { 39 Bq Isotropic }=8.9144 \text { Anisotropy }=3.4972 \\
\mathrm{XX}=7.7778 \mathrm{YX}=0.1167 \mathrm{ZX}=-0.5726 \\
\mathrm{XY}=0.3435 \mathrm{YY}=8.7527 \mathrm{ZY}=1.8924 \\
\mathrm{XZ}=0.1799 \mathrm{YZ}=1.3164 \mathrm{ZZ}=10.2128 \\
\text { Eigenvalues: } 7.44768 .049811 .2459 \\
40 \mathrm{~Bq} \text { Isotropic }=1.6786 \text { Anisotropy }=15.2492 \\
\mathrm{XX}=10.5675 \mathrm{YX}=2.1072 \mathrm{ZX}=-5.4420 \\
\mathrm{XY}=-0.2894 \mathrm{YY}=9.6071 \mathrm{ZY}=0.2248 \\
\mathrm{XZ}=-5.2183 \mathrm{YZ}=1.8698 \mathrm{ZZ}=-15.1389 \\
\text { Eigenvalues: }-16.25649 .447411 .8447\end{array}$ \\
\hline Mol7 & $\begin{array}{l}\text { 40 Bq Isotropic }=12.3185 \text { Anisotropy }=1.1257 \\
\mathrm{XX}=12.6349 \mathrm{YX}=0.0980 \mathrm{ZX}=0.2033 \\
\mathrm{XY}=0.3022 \mathrm{YY}=11.8211 \mathrm{ZY}=-0.1739 \\
\mathrm{XZ}=0.7387 \mathrm{YZ}=0.2598 \mathrm{ZZ}=12.4995 \\
\text { Eigenvalues: } 11.766012 .120513 .0690 \\
41 \text { Bq Isotropic }=1.5720 \text { Anisotropy }=15.2066 \\
\mathrm{XX}=9.0830 \mathrm{YX}=4.5689 \mathrm{ZX}=-2.0545 \\
\mathrm{XY}=2.4921 \mathrm{YY}=6.8852 \mathrm{ZY}=3.6795 \\
\mathrm{XZ}=-2.5185 \mathrm{YZ}=5.0451 \mathrm{ZZ}=-11.2523 \\
\text { Eigenvalues: }-12.67275 .679011 .7097 \\
42 \text { Bq Isotropic }=-1.6169 \text { Anisotropy }=33.0340 \\
\mathrm{XX}=1.5941 \mathrm{YX}=4.9983 \mathrm{ZX}=15.6048 \\
\mathrm{XY}=5.4978 \mathrm{YY}=-14.7943 \mathrm{ZY}=-0.9006 \\
\mathrm{XZ}=13.9020 \mathrm{YZ}=0.7638 \mathrm{ZZ}=8.3495 \\
\text { Eigenvalues: }-17.4348-7.821620 .4058\end{array}$ \\
\hline Mol8 & $\begin{array}{l}58 \mathrm{~Bq} \text { Isotropic }=3.5817 \text { Anisotropy }=14.9072 \\
\mathrm{XX}=10.6533 \mathrm{YX}=0.5431 \mathrm{ZX}=8.4295 \\
\mathrm{XY}=2.2866 \mathrm{YY}=7.2273 \mathrm{ZY}=0.0102 \\
\mathrm{XZ}=5.9209 \mathrm{YZ}=0.6736 \mathrm{ZZ}=-7.1355 \\
\text { Eigenvalues: }-9.67026 .895413 .5199 \\
59 \text { Bq Isotropic }=0.6561 \text { Anisotropy }=8.7459 \\
\mathrm{XX}=4.7690 \mathrm{YX}=1.0372 \mathrm{ZX}=2.1422 \\
\mathrm{XY}=3.7845 \mathrm{YY}=-0.9709 \mathrm{ZY}=6.6931 \\
\mathrm{XZ}=-0.6529 \mathrm{YZ}=2.6301 \mathrm{ZZ}=-1.8296 \\
\text { Eigenvalues: }-6.19251 .67426 .4867 \\
60 \mathrm{~Bq} \text { Isotropic }=2.8910 \text { Anisotropy }=19.8843 \\
\mathrm{XX}=13.2438 \mathrm{YX}=3.4598 \mathrm{ZX}=5.0488 \\
\mathrm{XY}=7.1119 \mathrm{YY}=0.4581 \mathrm{ZY}=10.8660 \\
\mathrm{XZ}=-0.8623 \mathrm{YZ}=3.3564 \mathrm{ZZ}=-5.0289 \\
\text { Eigenvalues: }-9.98282 .508616 .1471\end{array}$ \\
\hline
\end{tabular}

Nexo Revista Científica / Vol. 33, No. 01, pp. 109-120 / Junio 2020 
Theoretical back ground NMR Shielding and S-NICS method there are not theoreticallyor mathematically reports for the statistical approaches in NMR shielding and nucleus-independent-chemical-shift (S-NICS), Since the asymmetry $(\eta)$ and skew $(K)$ parameters have fluctuated in a short distances and in contrast are alternative in long distances.

\section{REFRENCES}

Mohammadian, N. K. Zare, M. Monajjemi. (2017). S-NICS Investigation for Heterocyclic Anticancer Compounds. Oriental Journal of Chemistry, 33(4), 1595-1602.

Ali, I.(2015). Heterocyclic scaffolds: centrality in anticancer drug development. Current drug targets, 16(7), 711-734.

Fathima, S.S.A., M.M.S. Meeran, E. Nagarajan. (2019). Design and synthesis of novel pyrazolone based coordination compounds: DNA synergy, biological screening, apoptosis, molecular docking and in-silico ADMET profile. Journal of Molecular Structure, 1197, 292-307.

Nakhaei, E., A. Nowroozi, F. Ravari. (2018). The hydrogen-bonded complexes of the 5-fluorouracil with the DNA purine bases: a comprehensive quantum chemical study. Structural Chemistry, 29(1), 69-80.

Hokmabady, L., H. Raissi, A. Khanmohammadi. (2016). Interactions of the 5-fluorouracil anticancer drug with DNA pyrimidine bases: a detailed computational approach. Structural Chemistry 27(2), 487-504.

Janganati, V.(2014). Heterocyclic aminoparthenolide derivatives modulate G2-M cell cycle progression during Xenopus oocyte maturation. Bioorganic \& medicinal chemistry letters, 24(8), 1963-1967.

Spiegel, K, A. Magistrato.(2006). Modeling anticancer drug-DNA interactions via mixed QM/MM molecular dynamics simulations. Organic \& biomolecular chemistry, 4(13),2507-2517.

Bienati, M., C. Adamo, V. Barone.(1999). Performance of a new hybrid Hartree-Fock/Kohn-Sham model (B98) in predicting vibrational frequencies, polarisabilities and NMR chemical shifts. Chemical physics letters, 311(1-2), 69-76.

Joshi, M. T.K. Ghanty. (2019). Prediction of a Nine- Membered Aromatic Heterocyclic 1, 4, 7triazacyclononatetraenyl anion and its Sandwich Complexes with Divalent Lanthanides. ChemistrySelec, 4(34), 9940-9946.

Martins, P.(2014). Organometallic compounds in cancer therapy: Past lessons and future directions. AntiCancer Agents in Medicinal Chemistry (Formerly Current Medicinal Chemistry-Anti-Cancer Agents), 14(9), 1199-1212.

Schleyer, P.v.R.. (1972). NJR v. Eikema Hommes. J. Am. Chem. Soc, 118, 6317.

Kruszewski, J. T. Krygowski.(1972). Definition of aromaticity basing on the harmonic oscillator model. Tetrahedron Letters, 13(36), 3839-3842.

Stępień, B.T. (2004). How far is the $\pi$-electron delocalization of the phenanthrene moiety modified in the aza-analogues and their N-oxides? Arkivoc, 3, 185-201.

Jiao, H. P.v.R. Schleyer. (1998). Aromaticity of pericyclic reaction transition structures: 
Skander, M. (2010). N-heterocyclic carbene-amine Pt (II) complexes, a new chemical space for the development of platinum-based anticancer drugs. Journal of medicinal chemistry, 53(5), 2146-2154.

L., S., (2017). Synthesis and Anticancer Evaluation of Some New 3-Benzyl-4,8Dimethylbenzopyrone Derivatives The Open Medicinal Chemistry Journal, 11,81-91.

Mollaamin, F. M. Monajjemi. (2012). DFT outlook of solvent effect on function of nano bioorganic drugs. Physics and Chemistry of Liquids, 50(5), 596-604.

Martin, N.H. K.H. Nance. (2002). Modeling through-space magnetic shielding over ethynyl, cyano, and nitro groups. Journal of Molecular Graphics and Modelling,, 21(1), 51-56.

Zakeri, M. M. Monajjemi. (2018). Effective molecules of some natural product as antidepressant and antihistamine drugs: A NMR study. Ukrainian Journal of Ecology, 8(2). 255-262.

SamieiSoofi, N., K. Zare, M. Monajjemi. (2018). Study of Gilan's environmental plants \& natural products as anti-cancer drugs: S-NICS method. Ukrainian Journal of Ecology,8(2), 217-224.

Chen, Z. (2005).Nucleus-independent chemical shifts (NICS) as an aromaticity criterion. Chemical reviews, 105(10), 3842-3888.

Aime, S., I. Bertini, C. Luchinat. (1996).Chapter 2 The Hyperfine Shift. Coord. Chem. Rev, 150, 29-75.

Monajjemi, M.. (2019). Aromaticity and Induced Current Study of C 8 H $8(n+2)(n=-6,-4,-2,0)$ : In the Viewpoint of Huckel's Rule. Journal of Structural Chemistry, 60(9), 1361-1374.

Esrafili, M.D., J. Beheshtian, N.L. Hadipour. (2009). 15 N CHEMICAL SHIFT CALCULATIONS AND NATURAL BONDING ORBITAL ANALYSES OF (BENZAMIDE) $\mathrm{n}=1-6$ CLUSTERS. Journal of Theoretical and Computational Chemistry, , 8(supp01), 973-982.

Sack, I.(1998). A 15 N-1 H dipolar CSA solid-state NMR study of polymorphous polyglycine (-CO-CD 2-15 NH-) n. Applied Magnetic Resonance, 17(2-3),413-431 Gu, Z. (1996). Hydrogen Bonding and Distance Studies of Amino Acids and Peptides Using Solid State 2D 1H- 13C Heteronuclear Correlation Spectra. Journal of the American Chemical Society,118(4), 822-829.

Cheeseman, J.R. (1996). A comparison of models for calculating nuclear magnetic resonance shielding tensors. The Journal of chemical physics, 104(14), 5497-5509.

Bauschlicher Jr, C.W. (1995). A comparison of the accuracy of different functionals. Chemical Physics Letters, 246(1-2),40-44.

Jalbout, A. S. Fernandez. (2002). Part II. Gaussian, complete basis set and density functional theory stability evaluation of the singlet states of $\mathrm{Cn}(\mathrm{n}=1-6)$ : energy differences, HOMO-LUMO band gaps, and aromaticity. Journal of Molecular Structure: THEOCHEM, 584(1-3) ,169-182.

Monajjemi, M. N.T. Mohammadian. (2015). S-NICS: An Aromaticity Criterion for Nano Molecules. Journal of Computational and Theoretical Nanoscience, 12(11), 4895-4914.

Nexo Revista Científica / Vol. 33, No. 01, pp. 109-120 / Junio 2020 